\title{
REFLEXIONES EN TORNO AL NUEVO RÉGIMEN COMPETENCIAL DERIVADO DEL ANTEPROYECTO DE LEY DE RACIONALIZACIÓN Y SOSTENIBILIDAD DE LA ADMINISTRACIÓN LOCAL
}

\author{
Jorge FERNÁNDEZ-MIRANDA \\ Departamento de Derecho Administrativo \\ Universidad Complutense de Madrid \\ jorgefm@der.ucm.es
}

\begin{abstract}
RESUMEN
El presente trabajo tiene como propósito abordar el estudio del nuevo régimen competencial articulado por el Anteproyecto de Ley de Racionalización y Sostenibilidad de la Administración Local con la finalidad de analizar sus virtudes y carencias. Siendo conscientes de la naturaleza del texto, nos parece relevante su análisis desde el momento en el que se trata de una de las modificaciones normativas con la que se pretende lograr la sostenibilidad del Estado y por su gran repercusión, toda vez que sus contenidos no ban dejado a nadie indiferente. Dicho lo cual, su estudio es importante con la finalidad de determinar si la nueva regulación de las competencias municipales - con origen y razón de ser en la modificación del art. 135 CE y en la necesaria estabilidad presupuestaria que exige- respetan el principio de autonomía local consagrado constitucionalmente. Dicho en otras palabras, una cosa es que el espiritu de la reforma sea de naturaleza eminentemente económica y otra bien distinta que dicho principio pueda actuar al margen de la propia realidad local y por encima de su propia configuración constitucional. Éstas y otras muchas cuestiones son objeto del presente estudio, advirtiendo que el modelo propuesto presenta una clara intención por conseguir la racionalización de la Administración Local, clarificar su régimen competencial y ganar en seguridad jurídica y coherencia normativa.
\end{abstract}

Palabras clave: autonomía local, municipio, ayuntamiento, reforma, Administración Local, sostenibilidad, racionalidad.

\section{ABSTRACT}

This piece of work has the goal to approach the new competence system penned by the Draft Law on Rationalization and Sustainability of Local Authorities in Spain, for the purpose to analyze its strengths and weaknesses. Knowing the essence of the text, we consider its study relevant since it deals with one of the regulation reforms aiming at achieving the State's sustainability, also because of its big impact, given that its contents haven't left anyone cold. Having said that, its study is important so as to establish whether the new regulation of the municipal competence -ori- 
ginating from article 135 of the Spanish Constitution and from the necessary budget balance implied - respects the principle of local autonomy self constitutionally validated. In other words, one thing is that the spirit behind the reform is of a mainly economic nature, and quite another thing is that the principle may apply the own local reality over its own constitutional configuration. Such and further questions are the purpose of study of this piece of work, warning us that the suggested pattern presents a clear intention to obtain the rationalization of the local government, to clarify its competence system and to better its legal conviction and rule consistency.

Keywords: local autonomy, municipality, town council, reform, local government, sustainability, rationality.

\section{ZUSAMMENFASSUNG}

Die vorliegende Arbeit hat zum Ziel, die neue Zuständigkeitsregelung, wie sie im Vorentwurf des Gesetzes zur Rationalität und Nachbaltigkeit der Ortsgemeindeverwaltung festgebalten wurde, auf ibre Stärken und Schwächen bin zu untersuchen. Die Untersuchung trägt der Natur des Textes Rechnung und erachtet ibre Analyse dadurch relevant, dass diese Gesetzesänderung zum Ziel hat, die Nachbaltigkeit des Staates zu gewäbrleisten. Zugleich bat die Zuständigkeitsregelung Auswirkungen, die alle gleichermaßen betreffen und niemanden kalt lassen. Mit der Untersuchung soll bestimmt werden, ob die Neuregelung der kommunalen Kompetenzen —die ibren Ursprung im Art. 135 der Spanischen Verfassung sowie in der dort geforderten notwendigen Ausgeglichbeit des Haushalts bat-das Prinzip der lokalen Gemeindeselbstverwaltung, welches in der Verfassung verankert ist, berücksichtigt. In anderen Worten: Es ist zu unterscheiden, ob der Reformgeist ausschließlich in den wirtschaftlichen Ursachen gründet oder ob dieses Reformprinzip auch unabhängig von der eigentlichen Gemeinderealität und von seiner verfassungsmäßigen Konstituierung handelt. Diese und viele andere Fragen sind Gegenstand der vorliegenden Untersuchung, die verdeutlichen möchte, dass das vorgeschlagene Modell die klare Absicht verfolgt, die Rationalität der Gemeindeverwaltung zu erzielen, die Regelung der Kompetenz der Gemeindeverwaltung zu klären sowie Rechtssicherbeit und gesetzliche Kompetenz zu gewinnen.

Schlüsselwörter: Lokale Selbstverwaltung, Ortsgemeinde, Rathaus, Reform, Gemeindeverwaltung, Nachhaltigkeit, Rationalität.

SUMARIO: I. INTRODUCCIÓN.-II. EL ESPÍRITU DE LA REFORMA.-III. LOS OBJETIVOS DE LA REFORMA.-IV. HACIA UN NUEVO RÉGIMEN COMPETENCIAL.-1. Introducción.-2. Los principios inspiradores del nuevo modelo competencial.-3. La clarificación de las competencias municipales.-A) Las competencias propias (ex arts. 25 y 26 LBRL) a la luz del ALRSAL.-a) Las competencias propias (ex nuevo art. 25 LBRL).-b) Las competencias propias mínimas u obligatorias (ex art. 26 LBRL).-B) Regulación de las competencias delegadas (art. 27 LBRL).-C) Supresión de las competencias complementarias (antiguo art. 28 LBRL).-D) Regulación de las competencias impropias: su significado, alcance y límites a su prestación.-V. CONCLUSIONES.-VI. BIBLIOGRAFÍA. 


\section{INTRODUCCIÓN}

Transcurridas casi tres décadas desde la aprobación de la Ley de Bases del Régimen Local ${ }^{1}$, cuyo texto ha sufrido numerosas e importantes modificaciones, parece inevitable admitir que el régimen local español está avocado a una nueva reforma en profundidad, cuya concreción se está haciendo esperar con motivo de las importantes dificultades que rodean a la misma. Sea como fuere, es una realidad que antes o después deberá abordarse, procurando racionalizar, desde muy diversos puntos de vista, el modelo vigente ${ }^{2}$. Para ello sería trascendental que la reforma que el gobierno pretende llevar a cabo fuera atemporal, es decir, centrada en la necesaria mejora de la Administración Local desde un punto de vista jurídico, económico y técnico, tratando de evitar un análisis sesgado y reducido a la perspectiva que ofrece la actual coyuntura económica. Máxime si tenemos en cuenta los nuevos principios constitucionales derivados del art. $135 \mathrm{CE}$ : estabilidad presupuestaria y sostenibilidad económica. Principios que exigirán una reinterpretación de la norma fundamental, en general, y del principio de autonomía local y su verdadero alcance y significado, en particular. En este sentido, siendo éste un aspecto importante en atención a las medidas a adoptar, debemos ser conscientes de que dicho enfoque - por sí solo considerado- puede suponer un mal diagnóstico del problema y la consecuente adopción de medidas inadecuadas por estar reducidas a lo puramente económico. En este punto, una de las importantes cuestiones que curiosamente no aborda el Anteproyecto está relacionada con la insuficiente financiación local (ex art. $142 \mathrm{CE}$ ), verdadero caballo de batalla y antesala de la existencia de autonomía.

Sea como fuere, el pasado mes de febrero se anunció 3 en qué consistiría la reforma, siendo nuestro propósito reflexionar en torno a lo que todavía es un mero Anteproyecto ${ }^{4}$, pero en el que se apuntan importantes ideas respecto al camino a seguir. La trascendencia de la misma, a pesar

${ }^{1}$ Ley 7/1985, de 2 de abril, reguladora de las bases del régimen local.

2 Desde un punto de vista competencial, organizativo y económico. Lo primero para clarificar el modelo, lo segundo para racionalizarlo reduciendo su número y lo tercero por la creencia - falsa en opinión de muchos sectores— de que el ámbito local está relacionado con un importante gasto a todas luces inasumible.

${ }^{3}$ Consejo de Ministros de 15 de febrero de 2013.

${ }^{4}$ Anteproyecto de Ley de racionalización y sostenibilidad de la Administración Local de 18 de febrero de 2013 (en adelante ALRSAL). 
de su carácter incipiente, nos lleva a realizar el presente trabajo, a lo largo del cual vamos a proceder a delimitar su origen y razón de ser, su espíritu y líneas maestras de actuación, centrando nuestra reflexión en torno a la nueva regulación de las competencias locales y a sus importantes consecuencias organizativas. Con ello pretendemos sumarnos a la importante discusión que rodea a la reforma, ahondando en la misma y analizando sus pros y sus contras, siempre desde una posición constructiva que permita su oportuna mejora.

\section{EL ESPÍRITU DE LA REFORMA}

El régimen local español ha evolucionado notablemente desde su aprobación mediante la Ley 7/1985, de 2 de abril, con la finalidad de introducir numerosas modificaciones, todas ellas tendentes a la mejora y profundización de la autonomía local constitucionalmente consagrada. Dicho lo cual, si ahora es importante centrarse en el espíritu de la nueva reforma planteada es por la deriva que se ha producido desde el surgimiento de la crisis económica ${ }^{5}$ en la que, aún hoy, seguimos inmersos. Es decir, si bien hace ya más de un lustro se discutía la necesidad de reformar el régimen $\operatorname{local}^{6}$ en la línea marcada por las anteriores reformas, lo cierto es que la razón de ser ha variado de una manera, podríamos decir, radical. No se trata ya de mejorar y profundizar en la autonomía local, sino que en la actualidad, y como consecuencia de la modificación del art. 135 $\mathrm{CE}$, todo gira en torno a la estabilidad presupuestaria y a la necesaria sostenibilidad de la Administración Local. Siendo su origen sobrevenido, ha llenado de razones al gobierno para abordar tan importante reforma, si bien desde un prisma sustancialmente diferente, pudiendo decir que nos encontramos ante una de las modificaciones del ordenamiento jurídico español que - a consecuencia de la crisis - pretende contribuir a la necesaria sostenibilidad del Estado.

\footnotetext{
5 Véanse Antonio EmbID IRUjo, «Crisis económica y reforma local», Anuario Aragonés de Gobierno Local, Zaragoza, Institución Fernando el Católico, 2011, y Rafael JimÉnez AsENSIO, «Las instituciones locales en tiempo de crisis: reforma institucional y gestión de recursos humanos en los gobiernos locales», Cuadernos de Derecho Local, núm. 26, Fundación Democracia y Gobierno Local, 2011.

6 Visto desde la perspectiva actual tiene especial interés el Libro Blanco para la reforma del gobierno local de 2005. Su lectura pone de manifiesto la clara diferencia de enfoque entre lo que proponía aquella reforma y lo que se propone en el actual Anteproyecto.
} 
En este orden, la propia Exposición de Motivos hace referencia ${ }^{7}$ a la reforma del art. $135 \mathrm{CE}^{8}$ señalando que: «El art. 135 de la Constitución Española, en su nueva redacción dada en 2011, recoge un principio de estabilidad presupuestaria como principio rector que debe presidir las actuaciones de todas las Administraciones Públicas. En desarrollo de este precepto constitucional se aprobó la Ley Orgánica 2/2012, de 27 de abril, de Estabilidad Presupuestaria y Sostenibilidad Financiera, que exige nuevas adaptaciones de la normativa básica en materia de Administración Local para la adecuada aplicación de los principios de estabilidad presupuestaria, sostenibilidad financiera o eficiencia en el uso de los recursos públicos locales. Todo ello exige adaptar algunos aspectos de la organización y funcionamiento de la Administración Local, así como mejorar su control económico-financiero»? .

7 «La reforma del art. 135 de la Constitución Española, en su nueva redacción dada en 2011, recoge un principio de estabilidad presupuestaria como principio rector que debe presidir las actuaciones de todas las Administraciones Públicas. En desarrollo de este precepto constitucional se aprobó la Ley Orgánica 2/2012, de 27 de abril, de estabilidad presupuestaria y sostenibilidad financiera, que exige nuevas adaptaciones de la normativa básica en materia de Administración Local para la adecuada aplicación de los principios de estabilidad presupuestaria, sostenibilidad financiera o eficiencia en el uso de los recursos públicos locales. Todo ello exige adaptar algunos aspectos de la organización y funcionamiento de la Administración Local, así como mejorar su control económico-financiero».

${ }^{8}$ BOE, núm. 233, de 27 de septiembre de 2011. Véanse Antonio José MarTí DEL MORAL, «La constitucionalización del principio de estabilidad presupuestaria», en Luis Cosculluela Montaner, Luis Medina Alcoz, María Hernando Rydings y Eloisa Carbonell PORRAS (coords.), Crisis económica y reforma del régimen local, Cizur Menor, Civitas Thomson Reuters, 2012, pp. 271-292; La Reforma Constitucional, Revista Teoría y Realidad Constitucional, núm. 29, 2012; Martín BAssols COMA, «La reforma del art. 135 CE y la constitucionalización de la estabilidad presupuestaria. El proceso parlamentario de elaboración de la reforma constitucional», REDA, núm. 155, 2012, pp. 21-41; Jorge GARCíA-ANDRADE GÓMEZ, «La reforma del art. 135 CE», RAP, núm. 187, 2012, pp. 31-66; Enrique ÁlvarEZ Conde y Clara Souto Galván (coords.), La constitucionalización de la estabilidad presupuestaria, Madrid, Instituto de Derecho Público, 2012, y María José Portillo Navarro y Valentín Merino Estrada (coords.), Crisis económica y entidades locales, Valladolid, Lex NovaThomson Reuters. 2012.

9 En este sentido ha recibido la denominación de «Anteproyecto de Ley de racionalización y sostenibilidad de la Administración Local», en el que queda patente su origen y razón de ser, y se evidencia la trascendencia que la estabilidad presupuestaria ha tenido y tiene en el actual proceso de reforma. En este punto, Sosa Wagner se muestra crítico advirtiendo que: «Digamos que de entrada no nos gusta nada el título, entre pedante y tecnocrático, que el gobierno ha puesto a su texto. Desde las discusiones sobre la Administración Local que protagonizó Antonio Maura a principios del siglo xx hasta las recientes del actual sistema democrático, pasando por las vividas en las dos Dictaduras y en la Segunda República, la regulación de los entes locales se ha llamado "Régimen Local" o "Derecho de las Administraciones Locales" (Francisco Sosa WAGner y Mercedes Fuertes, «Una reforma alicorta», El Mundo, viernes, 8 de marzo de 2013, p. 19). 
Su referencia es importante porque representa el motivo principal del Anteproyecto ${ }^{10}$, debiendo advertir desde este mismo momento que no es ni puede ser considerado como un fin en sí mismo, desde el instante en el que la autonomía local está consagrada constitucionalmente. Siendo cierto que corresponde al legislador concretar su contenido, no es menos cierto que éste viene determinado en sus líneas esenciales por el propio texto constitucional ${ }^{11}$. Asimismo debemos ser conscientes de que el modelo propuesto gira en torno a lograr la mencionada estabilidad, antesala de la eficiencia requerida y para lo cual la lealtad institucional y el oportuno control de la actividad municipal resultan cruciales, extremos éstos que han presidido $a$ sensu contrario la actividad municipal española. Finalmente debemos señalar que si bien las reformas articuladas hasta ahora tenían como eje la autonomía local y la manera de ampliar y consolidar la misma, en este momento tan importante principio (garantizado constitucionalmente) pasa a un segundo plano como consecuencia de su uso y, fundamentalmente, de su abuso.

Éste y no otro es el «espíritu» de la actual reforma ${ }^{12}$. Ahora bien, siendo evidente su importancia en atención a la introducción de coherencia,

${ }^{10}$ Especialmente crítico se muestra Velasco Caballero a la hora de analizar la propuesta de reforma y sus fundamentos empíricos. En este sentido advierte que las bases empíricas que permiten justificar la ineficiencia que se predica del ámbito local no están convenientemente justificadas. Al respecto véase Francisco Velasco Caballero, «Sobre el Anteproyecto de Ley de racionalización y sostenibilidad de la Administración Local: una reforma sin fundamento empírico y, por tanto, arbitraria», en bttp://www.idluam.org/images/files/boletines/index_44_3_archivos/Page426.htm, Instituto de Derecho Local-UAM, 2013.

${ }^{11}$ Véanse Joaquín GARCía Morillo, La configuración constitucional de la autonomía local, Madrid, Diputación de Barcelona-Marcial Pons, 1998; José Esteve PARDO, «Garantía institucional y/o función constitucional en las bases del régimen local», REDC, núm. 31, enero-abril de 1991, pp. 125-147; Javier GARCíA ROCA, «El concepto actual de autonomía local según el bloque de constitucionalidad», REALA, núm. 282, enero-abril de 2000, p. 27, y Javier GARCÍA FERNÁNDEZ, «Derecho constitucional y entidades locales. Sistema de fuentes y autonomía como fundamentos constitucionales básicos del Derecho local», Parlamento y Constitución. Anuario de las Cortes de Castilla-La Mancha, núm. 6, 2002, pp. 205-240. En contra, Luciano Parejo Alfonso, Garantía institucional y autonomias locales, Madrid, IEAL, 1981; ÍD., «La autonomía local», REALA, núm. 229, enero-marzo de 1986, pp. 11-12; íD., «Comunicación», en Joaquín García Morillo, La configuración constitucional de la autonomía local, op. cit.; ÍD., «La autonomía local en la Constitución», en Santiago MuÑoz Machado (dir.), Tratado de Derecho Municipal, t. I, Madrid, Civitas, 2003; íD., «La garantía institucional y las competencias locales», en Informe sobre el gobierno local, Madrid, MAP-Fundació Pi-Sunyer, 1992, pp. 355 y ss.; José Luis CARRO FERNÁNDEZ-VALMAYOR, «El debate sobre la autonomía municipal», RAP, núm. 147, septiembre-diciembre de 1998, pp. 59-96; Francisco Velasco CaballeRO, «Autonomía municipal», ponencia presentada en el II Congreso de la Asociación Española de Profesores de Derecho Administrativo, Santander, 2 de febrero de 2007, y Jorge FERnÁndeZ-Miranda FERnÁndeZ-Miranda, «El principio de autonomía local y la posible superación de la teoría de la garantía institucional», $R A P$, núm. 175, 2008, pp. 113 y ss.

${ }^{12}$ De ahí que los títulos competenciales que esgrime la reforma se centren no sólo 
claridad normativa y seguridad jurídica ${ }^{13}$, ello no supone ni justifica la supresión de la autonomía constitucionalmente consagrada. Es decir, en nuestra opinión, el redimensionamiento de la autonomía local no puede tener como propósito y consecuencia su supresión. La ley podrá ocuparse - dentro de los parámetros constitucionales- de dar un contenido más o menos amplio a la mencionada autonomía, pero no puede erradicar su contenido esencial ${ }^{14}$.

Una cosa es adecuar la autonomía a las capacidades del municipio y al nuevo paradigma constitucional, y otra bien distinta erradicar in totum, o hasta el punto de hacer irreconocible, dicho principio. Siendo cierto que la estabilidad presupuestaria y la sostenibilidad de la Administración son dos principios en base a los cuales tendremos que reinterpretar y releer la Constitución Española, no es menos cierto que ésta consagra otros muchos principios - entre los cuales se encuentra la autonomía local y la suficiencia financiera- que deberán ser considerados oportunamente en dicho proceso. En este punto, a lo largo del presente trabajo debemos plantearnos si la nueva regulación de las competencias municipales y sus importantes consecuencias organizativas respetan el principio de autonomía local consagrado constitucionalmente. Y ello por una simple pero rotunda razón: que la consecuencia que se deriva de la evaluación negativa de los servicios - en términos económicos- y la centralización de los mismos supone vaciar de contenido la autonomía, por cuanto el municipio en cuestión queda al margen de dicha actuación, hasta al punto de que pierde la titularidad de la competencias que con carácter previo y de manera expresa le atribuye la LBRL. Dicho en otras palabras, una cosa es que el espíritu de la reforma sea de naturaleza eminentemente económica ${ }^{15}$, y otra bien

en el art. 149.1.18 CE, sino que se haga referencia a los arts. 149.1.13 (bases y coordinación de la planificación general de la actividad económica) y 149.1.14 (hacienda general y deuda del Estado).

${ }^{13} \mathrm{Al}$ respecto debe advertirse, como se verá a lo largo del presente trabajo, que, siendo ésta la intención, no siempre se logra el objetivo. En este sentido será necesaria una mejora del texto en atención a la técnica legislativa y a la regulación de algunas de las importantes cuestiones que regula. Más allá, por supuesto, de que se pueda o no compartir la línea trazada en la reforma.

${ }^{14} \mathrm{Al}$ respecto véase Jorge Fernández-Miranda FernándeZ-Miranda, «El principio de autonomía local y la posible superación de la teoría de la garantía institucional», op. cit., pp. 113-156.

${ }^{15}$ Es más, como advierte Embid Irujo: «La crisis económica no ha sido causada por las estructuras del régimen local en España, pero muchas voces postulan su reforma para superar la crisis. El trabajo discute la seriedad del debate actual y sitúa el problema de la organización del territorio en su propio contexto, intemporal en relación a la crisis, postulando un método distinto para la reforma del gobierno local. La necesidad de alcanzar un nuevo sis- 
distinta que pueda representar un fin en sí mismo al margen de la propia realidad local y por encima de su propia configuración constitucional. De tal manera que la reforma debe perseguir la necesaria racionalización del modelo, pero salvaguardando la autonomía local constitucionalmente consagrada y, por ende, respetando la esencia de lo que es y representa para los administrados el ámbito municipal. En este sentido invita a reflexionar sobre la propia existencia del municipio y su significado.

Sea como fuere, para poder evaluar las virtudes y los posibles excesos del modelo propuesto vamos a proceder con carácter previo a analizar — aunque sea someramente- sus objetivos, dedicando nuestra reflexión posterior al análisis del nuevo mapa competencial, de su régimen jurídico y de sus importantes consecuencias.

\section{LOS OBJETIVOS DE LA REFORMA}

Siendo cierto que la clave de bóveda de la reforma estriba en la necesaria estabilidad presupuestaria, verdadera «idea fuerza» de la misma, no es menos cierto que, en pro de lograr la misma, el Anteproyecto —en su Exposición de Motivos- propone una triple línea de actuación que abarca la reforma de la Ley Reguladora de las Bases del Régimen Local, teniendo también importantes consecuencias sobre la Ley de Haciendas Locales y sobre el Estatuto Básico del Empleado Público. En este sentido se abren tres frentes: uno competencial, otro organizativo y otro relativo al necesario control financiero y presupuestario de la actividad municipal. Este último debe ser entendido como un fin en sí mismo, al tiempo que - por su propia naturaleza - pretende y permite la correcta consecución de los fines perseguidos por los otros dos, caracterizándose, por tanto, por su carácter transversal. Unos y otros guardan estrecha relación, con independencia de que, por razones didácticas, tendamos a diferenciarlos. No se trata de compartimentos estancos, de tal manera que la reforma cobra

tema de financiación parece evidente en el nuevo marco de equilibrio presupuestario para las entidades locales». Excelente resumen al trabajo Antonio EMBID IRUJO, «Crisis económica y reforma local», op. cit., p. 443. En nuestra opinión, las razones económicas siempre han estado ahí. Dicho en otras palabras, la necesaria racionalización del régimen local ha sido una constante en el tiempo, si bien es una cuestión que pasa inadvertida hasta el instante en el que se convierte no en una necesidad, sino en una obligación. En este sentido resulta muy esclarecedora la obra colectiva de María José Portillo NAVArRo y Valentín Merino EstraDA (coords.), Crisis económica y entidades locales, op. cit. En ella se pretende abordar de una manera directa la problemática financiación local y las medidas a adoptar ante la crisis. 
pleno sentido tras el análisis de todos y cada uno de ellos, por separado y en su conjunto.

Llegados a este punto a nosotros nos interesa estudiar el nuevo régimen competencial, analizando sus novedades, sus posibles excesos y sus consecuencias sobre la propia concepción del municipio y de la autonomía local constitucionalmente consagrada y sobre la planta orgánica municipal.

\section{HACIA UN NUEVO RÉGIMEN COMPETENCIAL}

\section{Introducción}

En un Estado compuesto como el nuestro, estructurado en tres niveles —estatal, autonómico y local_, el reparto de competencias resulta esencial. Es más, en nuestra opinión ésta es una de las grandes cuestiones pendientes de nuestro modelo, en la medida que favorece la proliferación de «Reinos de Taifas» por su falta de claridad y la inseguridad jurídica que de ello se deriva ${ }^{16}$. En este punto, a la hora de fijar la mirada sobre el ámbito local, y conscientes de que la Constitución guarda silencio sobre dicho extremo, resulta igualmente crucial, máxime cuando constitucionalmente se reconoce la autonomía local, una de cuyas consecuencias es el ejercicio de ciertas competencias que les permita la defensa de sus propios intereses.

La regulación de las competencias locales representa una problemática conocida por todos ${ }^{17}$ y que ahora el Anteproyecto trata de abordar buscando clarificar y racionalizar el modelo, haciendo más eficientes y económicos los servicios públicos locales, y pretendiendo erradicar las duplicidades innecesarias, entre otras muchas cuestiones.

Por un lado tenemos la clarificación del modelo existente, cuestión que se aborda estableciendo un nuevo marco jurídico que lo haga plausible. Por otro lado destaca la inequivoca intención de adecuar el ejercicio de competencias por parte del municipio a su capacidad y, lo que es más importante, a que el mismo responda a criterios de eficacia y eficiencia, o, dicho en

\footnotetext{
${ }^{16}$ No sólo por el carácter bifronte del régimen local, sino por las dificultades que se derivan del modelo competencial auspiciado por la LBRL. Respecto al problema derivado de la distribución de competencias entre el Estado y las Comunidades Autónomas véase Miguel SÁNCHEZ MORÓN, «La distribución de competencias entre el Estado y las Comunidades Autónomas en materia de Administración Local», en Santiago Muñoz Machado (dir.), Tratado de Derecho Municipal, t. I, Madrid, Iustel, 2011, pp. 337 y ss.

${ }^{17}$ Francisco Sosa Wagner, «Los principios del régimen local», en Santiago MuÑoz Machado (dir.), Tratado de Derecho Municipal, t. I, Madrid, Iustel, 2011, pp. 211 y ss.
} 
otras palabras, a criterios puramente económicos — como la economía de escala- para determinar la propia calidad del servicio.

Lo primero es loable, por no decir imprescindible. Lo segundo encierra ciertos problemas desde la perspectiva de la autonomía local constitucionalmente consagrada y de las consecuencias evidentes para muchos municipios españoles: el vaciamiento competencial y el indudable efecto sobre la actual planta orgánica municipal. Todo ello justificado en razones económicas (ex art. $135 \mathrm{CE}$ ) pero no en atención a la autonomía (ex arts. 137 y $140 \mathrm{CE}$ ) ni a la suficiencia financiera (ex art. $142 \mathrm{CE}$ ) como elemento esencial de la propia autonomía y verdadero caballo de batalla que, una vez más, queda fuera del propio modelo.

Siendo cierto que hay que racionalizar el número de municipios españoles, dicho proceso no puede pasar simplemente por el exclusivo filtro económico, máxime cuando la propia Constitución reconoce la existencia de municipios que se organizan en régimen de concejo abierto. Asimismo plantea dudas que el modelo busque dicha racionalización de manera indirecta y como consecuencia ineludible de la dupla competencias-capacidad de gestión, cuyo inevitable resultado será la supresión de municipios. Dicha relación está directamente conectada a la financiación local, cuestión que se omite, haciendo simple referencia al coste del servicio para determinar su viabilidad. Y al margen, por supuesto, de las singularidades que se derivan de la diversidad del régimen local español (desde un punto de vista poblacional, geográfico, turístico etc.) que exigiría relativizar la calidad del servicio en atención al coste real en términos «subjetivos» del mismo.

Dicho lo cual, y sin entrar a analizar todavía el modelo propuesto, debemos advertir desde este mismo instante que tiene importantes consecuencias no sólo sobre las competencias strictu sensu, sino sobre la configuración de la propia autonomía local, así como en relación a la organización municipal, todo ello como consecuencia de la capacidad de gestión y sus importantes efectos a nivel competencial. Es decir, lo que se está discutiendo es el propio concepto del municipio hasta ahora conocido, planteando dudas sobre lo que al respecto consagra la norma fundamental. En definitiva, mientras que la Constitución no prohíbe — con matizaciones- la supresión de municipios ${ }^{18}$ (cuestión distinta sería la discusión de la titularidad de dicha competencia) no permite que, manteniendo los mis-

${ }^{18}$ Manuel Rebollo Puig, «La crisis económica y la posibilidad de reducir el número de municipios», en Luis Cosculluela Montaner, Luis Medina Alcoz, María Hernando Rydings y Eloisa CARBOnell PorRas (coords.), Crisis económica y reforma del régimen local, op. cit., pp. 195-224. 
mos, se vulnere la autonomía local que tienen constitucionalmente reconocida $^{19}$. Cuestiones todas ellas sobre las que volveremos al hilo del estudio del nuevo modelo competencial, no sin antes abordar los principios inspiradores del mismo.

\section{Los principios inspiradores del nuevo modelo competencial}

En aras a lograr la mencionada clarificación del modelo, la propuesta hace propia la máxima «una Administración, una competencia». Siendo este principio de sentido común, lo cierto es que la realidad que se derivaba del régimen jurídico establecido por la LBRL supuso la implantación de un modelo sumamente complejo que ha generado importantes disfuncionalidades ${ }^{20}$, propiciando situaciones de concurrencia competencial, duplicidad en la prestación de servicios o prestación de competencias impropias. Todo ello ha incrementado el gasto de una manera inaceptable, afectando a su vez al conocimiento del titular de las competencias, poniendo en entredicho la necesaria seguridad jurídica y, lo que es más importante, introduciendo serias dificultades como consecuencia de todo ello a la imputación de responsabilidad por los perjuicios que se pudieran derivar de la actividad local.

Siendo todo lo dicho cierto y exigiendo, por tanto, una actuación inmediata que permita introducir cordura donde no la hay, no es menos cierto que el nuevo modelo supone un diagnóstico de la realidad local que debe ser objeto de detenido estudio con la finalidad de determinar su significa-

${ }_{19} \mathrm{Al}$ respecto es muy importante atender a la teoría de la garantía institucional en relación con la autonomía local. Sobre su significado y alcance véanse Joaquín GARCíA MoriLLO, La configuración constitucional de la autonomía local, op. cit.; José EsTEVE PARDO, «Garantía institucional y/o función constitucional en las bases del régimen local», op. cit., pp. 125-147; Javier GARCÍA ROCA, «El concepto actual de autonomía local según el bloque de constitucionalidad», op. cit., p. 27, y Javier GARCíA FERNÁNDEZ, «Derecho constitucional y entidades locales. Sistema de fuentes y autonomía como fundamentos constitucionales básicos del Derecho local», op. cit., pp. 205-240. En contra, Luciano PARejo Alfonso, Garantía institucional y autonomías locales, op. cit.; ÍD., «La autonomía local», op. cit., pp. 11-12; íD., «Comunicación», en Joaquín GARCíA MORILLO, La configuración constitucional de la autonomía local, op. cit.; íD., «La autonomía local en la Constitución», op. cit.; íD., «La garantía institucional y las competencias locales», op. cit., pp. 355 y ss.; José Luis Carro FERnández-ValmaYor, «El debate sobre la autonomía municipal», op. cit., pp. 59-96; Francisco Velasco CaballeRO, «Autonomía municipal», op. cit., y Jorge FERNÁNDEZ-MirANDA FERnÁNDEZ-MirANDA, «El principio de autonomía local y la posible superación de la teoría de la garantía institucional», op. cit., pp. 113 y ss.

${ }^{20}$ Como así se ha señalado en la Exposición de Motivos del Anteproyecto. 
do, alcance y régimen jurídico. En este sentido, la gran preocupación que subyace está estrictamente relacionada con el municipio en atención a los siguientes criterios:

- La falta de claridad del modelo competencial.

- La existencia de duplicidades que suponen un incremento del coste de los servicios públicos.

- La aparición de una superestructura organizativa que debe ser objeto de revisión.

- El elevado coste de los servicios locales-municipales.

- La falta de capacidad de los que tienen una población menor a los 20.000 habitantes para prestar los mismos en atención a unos parámetros puramente económicos.

$\mathrm{Al}$ respecto debemos preguntarnos si es correcto y va a suponer una solución al problema existente ${ }^{21}$, y si las medidas que se quieren adoptar resultan respetuosas con la autonomía local constitucionalmente consagrada. Para resolver la primera y segunda cuestión el Anteproyecto pone el énfasis en articular un nuevo modelo competencial; respecto a las dos últimas, caracterizadas por ser representativas del verdadero «caballo de batalla» a la luz de la Exposición de Motivos y del propio articulado, busca lograr unos servicios municipales basados en la eficiencia económica ${ }^{22}$. Para lo cual articula un sistema con el que determinar su coste (real decreto del gobierno) y el procedimiento a seguir en caso de que no se obtenga una evaluación positiva, pudiendo avanzar el resultado, máxime cuando se vienen a establecer conceptos económicos como la «economía de escala» a los efectos de analizar los servicios municipales.

${ }^{21}$ «Por un lado, el déficit municipal se centra, fundamentalmente, en los grandes y medianos municipios. Por lo que, aun siendo correcto el diagnóstico, el ahorro económico no es tan relevante y los perjuicios que se pueden ocasionar pueden ser enormes y previsiblemente contrarios a su autonomía. Por otro lado, potenciar la provincia parece una buena respuesta, pero ¿se puede producir a costa del municipio, sin que se reestructure su planta orgánica? Máxime cuando el modelo propuesto avoca a ello [...] c) Se podría resolver el problema centrándose en la planta orgánica de las mancomunidades existentes (un total de 1.021 en la actualidad)». Al respecto resulta interesante la obra de Manuel ReBOLLO PuIG, «La crisis económica y la posibilidad de reducir el número de municipios», op. cit., pp. 195 y ss.

${ }^{22}$ Respecto a la tercera, se está haciendo referencia al problema derivado de la Administración instrumental y su necesaria racionalización. Asimismo, aunque en menor medida, se centra en la necesidad de reducir/suprimir las entidades locales menores y las mancomunidades de municipios. Cuestiones éstas que exceden al presente trabajo, aunque alguna referencia a ellas haremos. 
En este instante debemos realizar dos observaciones al menos. Por un lado, que la reforma articulada supone centrar la atención en los pequeños y medianos municipios (hasta los 20.000 habitantes), sobre los que recaen gran parte de las medidas articuladas ${ }^{23}$ (al menos las más duras), más allá de que todos los municipios van a tener que realizar una evaluación de los servicios municipales (disposición adicional sexta). Resulta curiosa la preocupación económica, las medidas adoptadas, los destinatarios de las mismas y el hecho de que el déficit local se centra fundamentalmente - en término absolutos- en los municipios que superan dicha franja poblacional. Es decir, siendo evidente la aparente falta de capacidad de gestión, no es menos cierta la importancia que tiene la concepción natural del municipio y las graves consecuencias que se puedan derivar de su supresión.

Por otro lado, y relacionado con lo anterior, que el modelo auspiciado no se compagina con otras medidas de naturaleza organizativa ${ }^{24}$, esenciales en atención a la autonomía local constitucionalmente consagrada. Es decir, no es de recibo que no se produzca un replanteamiento de la planta orgánica municipal cuando las medidas adoptadas convergen en dicha dirección, pero de manera indirecta. Lo que choca con el concepto constitucional y legal que se tiene del municipio, con su autonomía, suficiencia financiera y con el sustrato sentimental que subyace a dicha realidad. Sustrato éste que no debe impedir una racionalización orgánica del modelo, pero que debe tomarse en consideración a los efectos de determinar el verdadero alcance de la misma y de la solución a adoptar. En este sentido llama la atención la supresión de las entidades locales menores, pues ésta podría ser una de las muchas fórmulas para replantear la planta orgánica municipal sin suprimir in totum los municipios existentes hasta ahora ${ }^{25}$. Como parte de un nuevo municipio, que no suponga la ruptura de su uni-

${ }^{23}$ Ya que para los que tengan más de dicha cifra, en caso de no tener estabilidad presupuestaria, se exige la aprobación de un plan de viabilidad. Por el contrario, si se trata de un municipio con menos de 20.000 habitantes se prevé la elevación obligatoria (centralización), con pérdida de titularidad, de la competencia (art. 26 LBRL). Afectando, por supuesto, al ejercicio de otro tipo de competencias (arts. 25 y 27 LBRL).

${ }^{24}$ Sobre ello incide acertadamente Luis Cosculluela MonTANER, «Presentación», en Luis Cosculluela Montaner, Luis Medina Alcoz, María Hernando Rydings y Eloisa CarBONELl PoRRAs (coords.), Crisis económica y reforma del régimen local, op. cit., pp. 25 y ss. Resultan también interesantes las respuestas dadas en el entorno europeo (ibid.). Asimismo, Manuel Rebollo Puig, «La supresión de los pequeños municipios: régimen, alternativas, ventajas e inconvenientes», REALA, núm. 308, pp 151-206.

${ }^{25} \mathrm{Al}$ respecto véase Manuel Rebollo Puig, «La crisis económica y la posibilidad de reducir el número de municipios», op. cit., p. 203. 
dad, pero que permita su participación y el reconocimiento de una cierta personalidad jurídica. Sobre todo ello volveremos más adelante.

De momento se trata — simplemente- de ir introduciendo dudas razonables respecto al modelo que se pretende articular y a sus importantes consecuencias organizativas, competenciales o de control. Partiendo de las mismas, y con independencia de que no tenemos por qué compartir sus planteamientos, estaremos en mejor disposición de abordar el estudio del nuevo modelo competencial propuesto y sus posibles excesos en relación a la autonomía local constitucionalmente consagrada.

Volviendo sobre la regulación planteada desde la perspectiva de su necesaria clarificación, debemos destacar su importancia porque se procede a determinar de una manera clara y tajante las competencias propias y delegadas; asimismo, porque se suprimen las competencias complementarias (se suprime el contenido del art. 28 LBRL) y, finalmente, porque se procede a definir las competencias impropias, su significado, alcance y límites a su prestación. Este primer acercamiento es, en nuestra opinión, sumamente positivo, siendo, sin embargo, necesario realizar un estudio más pormenorizado con la finalidad de determinar su resultado y si el mismo es acorde con la clarificación competencial que se propugna.

\section{La clarificación de las competencias municipales}

A tenor del ALRSAL nos vamos a encontrar con dos tipos de competencias: propias y delegadas, a las que se podrán sumar las ahora sí reguladas competencias impropias (ex nuevo apartado 4 del art. 7 LBRL). En cuanto a las competencias propias, advertir que podrán ser de dos tipos: propias mínimas u obligatorias (ex art. 26) y propias (ex art. 25) en los términos de la legislación del Estado y de las Comunidades Autónomas en las materias que se determinan. Desaparecen, por tanto, las conocidas hasta ahora como competencias complementarias (ex art. 28 LBRL, que queda derogado in totum).

En lo que se refiere a las competencias propias y delegadas, advertir que el régimen jurídico de su ejercicio se mantiene intacto (autonomía y responsabilidad, en el primer caso, y en los términos establecidos en la disposición o en el acuerdo de delegación, en el segundo), con la única salvedad de la inclusión en el apartado tercero del art. 7 LBRL de la necesaria eficiencia en el ejercicio de las competencias delegadas. Lo que resulta curioso no por su inclusión (acorde con el espíritu de la reforma), sino por 
no extenderla, al menos expresamente, a las competencias propias. Cuestión que, sin embargo, sí hace con carácter posterior el apartado 3 del art. 25, yendo más allá al referirse a la eficiencia, estabilidad y sostenibilidad financiera. Tratándose, por tanto, de un mero problema de coherencia y de técnica legislativa que debería ser depurado, pero sin afectar a la gran máxima de la reforma, centrada fundamentalmente en la necesaria estabilidad presupuestaria y, por ende, en la eficacia, eficiencia y sostenibilidad de la Administración Local.

\section{A) Las competencias propias (ex arts. 25 y 26 LBRL) a la luz del ALRSAL}

Respecto a las competencias propias debemos advertir - como ya hemos expresado con anterioridad- la diferenciación entre las derivadas de los arts. 25 y 26. Las primeras, en los términos de la legislación del Estado y de las Comunidades Autónomas sobre determinadas materias expresamente señaladas, y las segundas, las conocidas como mínimas u obligatorias. Veamos cada una por su lado siguiendo para ello el orden del articulado.

\section{a) Competencias propias (ex nuevo art. 25 LBRL)}

Son objeto de regulación en el art. 25 LBRL, en cuya redacción se han introducido importantes novedades que pretenden lograr la mencionada clarificación del modelo competencial. En este sentido podemos destacar lo siguiente.

En el apartado primero se incluye una adición trascendental para la comprensión del nuevo modelo. En dicho precepto se hace referencia a que el municipio, para la gestión de sus intereses y en el ámbito de sus competencias, puede promover actividades y prestar los servicios públicos que contribuyan a satisfacer las necesidades y aspiraciones de la comunidad vecinal en los términos previstos en este artículo. Semejante referencia no es baladí, por cuanto ello supone evitar interpretaciones que con anterioridad permitieron el ejercicio de ciertas competencias impropias. Asimismo debemos prestar atención a la redacción dada al apartado tercero, en el que, manteniéndose la reserva de ley para la determinación de dichas competencias, se añade que debe evaluarse la conveniencia de la implanta- 
ción del servicio local conforme a los principios de descentralización, eficiencia, estabilidad y sostenibilidad financiera ${ }^{26}$.

$\mathrm{Al}$ respecto debemos plantearnos si a sensu contrario, es decir, si no se produce dicha conveniencia, puede inferirse que no se podrá prestar la misma. Dentro del espíritu de la reforma y de las consecuencias que al respecto se determinan sobre el ejercicio de las competencias delegadas e impropias parecería lógico pensar que debe ser así. Máxime si tenemos en cuenta la gran preocupación subyacente respecto a los municipios de menos de 20.000 habitantes y su «aparente» falta de capacidad, cuyas consecuencias más relevantes se derivan en cuanto al ejercicio de las competencias propias mínimas u obligatorias. Sea como fuere llama la atención que un municipio que no cumpla con los requisitos económicos establecidos pierda la titularidad de las competencias mínimas u obligatorias y que, al mismo tiempo, ejerza sus competencias propias ex art. $25 \mathrm{LBRL}^{27}$. Pudiendo no resultar conveniente desde una perspectiva estrictamente económica, no se puede obviar que la propia Constitución recoge el principio de suficiencia financiera que debe, en todo caso, garantizar la defensa de los intereses municipales y, en consecuencia, el ejercicio de sus competencias propias, con autonomía y plena responsabilidad. Lo que supone una contraditio in terminis que habrá que resolver caso por caso.

Por otro lado, y directamente relacionado con la necesidad de determinar la conveniencia exigida en el inciso final del apartado tercero, se hace expresa referencia en los apartados cuarto y quinto - y ello es trascendental - a las medidas con las que dar cumplimiento y hacer efectivos los principios de eficiencia, estabilidad y sostenibilidad financiera mencionados. A saber:

a) Los proyectos de ley estatales deben acompañarse de un informe favorable del Ministerio de Hacienda y Administraciones Públicas en el que se acredite el cumplimiento de los requisitos señalados ${ }^{28}$.

${ }^{26}$ La cursiva responde a la nueva redacción, en la que de manera más concreta se establecen unos límites a la posible delegación y en la que la estabilidad y sostenibilidad financiera cobran especial relevancia.

${ }^{27}$ La cuestión estriba en determinar hasta dónde alcanza la concepción que el gobierno tiene de la capacidad necesaria para prestar los servicios municipales.

${ }^{28} \mathrm{Al}$ respecto llama la atención que esta previsión afecte sólo a las Leyes del Estado. Debería extenderse a las leyes autonómicas (informe favorable de la Consejería equivalente), por cuanto es en dicho ámbito donde surge el mayor problema, dado el reparto de competencias existente en la Constitución entre uno y otro nivel. Máxime cuando el párrafo anterior del apartado 4 y el apartado 5 se refieren a la ley en sentido amplio. 
b) La ley, con independencia de que sea estatal o autonómica, debe ir acompañada de una memoria económica que refleje el impacto sobre los recursos financieros de las Administraciones Públicas afectadas y el cumplimiento de los principios de estabilidad, sostenibilidad financiera y eficiencia del servicio a la actividad. Debe prever la dotación de los recursos necesarios para asegurar la suficiencia financiera de las entidades locales, sin que ello pueda conllevar, en ningún caso, un mayor gasto de las Administraciones Públicas, lo que es importante, por cuanto, dada la intención del gobierno, se deberá respetar la «economía de escala», poniendo en tela de juicio dos cosas al menos: por un lado, los criterios en virtud de los cuales se determinará el coste real; por otro, las dudas respecto a los municipios intervenidos o con un plan de viabilidad. Todo ello como consecuencia del gran debate: la capacidad real de los municipios para prestar servicios públicos en atención a sus medios económicos, materiales y personales.

c) Impedirá las duplicidades administrativas, para lo cual deberá establecer con precisión el servicio o actividad local, con estricta separación de las competencias estatales y autonómicas.

En tercer lugar se incluye una referencia en el apartado segundo que resulta esclarecedora. A la hora de señalar las materias sobre las que el municipio va a ejercer dichas competencias, así definidas en la legislación anterior, se concreta ahora que el municipio las ejercerá en todo caso como competencias propias, en los términos de la legislación del Estado y de las Comunidades Autónomas ${ }^{29}$. Esta referencia expresa a su naturaleza jurídica - como competencias propias - tiene una importancia capital en la clarificación del modelo, pues elimina ab initio cualquier otra interpretación sobre las mismas.

En cuarto lugar llama también la atención la nueva redacción dada a las competencias que «en todo caso» ejercerá el municipio como competencias propias en los términos de la legislación del Estado y de las Comunidades Autónomas. En este punto se observa una cierta mejora en la redacción de las materias, las cuales deben ser entendidas a su vez como un mínimo o como un listado númerus apertus. Asimismo debemos destacar la concreción de la competencia en la protección del medio ambiente,

${ }^{29}$ Las materias han sufrido asimismo modificaciones, siendo la más relevante la relativa a la educación. Si bien sobre ello volveremos más adelante. En este momento nos interesa destacar la calificación de dichas competencias como propias. 
referida expresamente al medio ambiente urbano; la supresión de la participación en la gestión de la atención primaria de la salud y de la defensa de usuarios y consumidores, y la reducción de la competencia en materia educativa $^{30}$. Extremos estos que plantean importantes retos desde un punto de vista no sólo local, sino también regional, por cuanto son elevadas a dicho nivel, siendo especialmente relevantes las relativas a la asistencia sanitaria y a la educación. En esta línea resulta importante la disposición transitoria octava, «Asunción por las Comunidades Autónomas de las competencias relativas a la salud y la educación», en la que se prevé el procedimiento y plazos para hacerla efectiva, así como a sus consecuencias financieras. Dicho lo cual sería importante mejorar su redacción, así como advertir de la realidad derivada, en uno y otro caso, respecto a la asunción de los costes derivados de su ejercicio.

\section{b) Competencias propias minimas u obligatorias (ex art. 26 LBRL)}

La nueva regulación que se da al art. 26 LBRL pone de manifiesto la intención del gobierno de priorizar el régimen de prestación de servicios públicos no sólo en atención a su eficiencia, sino que sin ésta y sin la necesaria estabilidad presupuestaria no se permitirá el ejercicio de otras competencias propias, delegadas o impropias (por ese orden), lo que responde a las exigencias derivadas de la necesaria eficiencia, estabilidad presupuestaria y sostenibilidad financiera.

En este sentido, y más allá de la supresión de la competencia relativa al control de alimentos y bebidas ${ }^{31}$ (anteriormente exigida para todos los municipios), y de la competencia relativa a la prestación de servicios sociales $^{32}$ (ahora reducida a la evaluación e información de situaciones de necesidad social y la atención inmediata a personas en situación o riesgo de exclusión social), el espíritu sigue siendo el mismo, en la medida que se establece un listado de competencias en atención al criterio poblacional. Por otro lado, se añade un párrafo final al apartado 1 del art. 26 en el que se señala expresamente que «la asistencia de las diputaciones a los municipios prevista en el art. 36 se dirigirá preferentemente al estable-

${ }^{30}$ Consistente ahora en «participar en la vigilancia del cumplimiento de la escolaridad obligatoria y cooperar con las administraciones educativas correspondientes en la obtención de los solares necesarios para la construcción de nuevos centros escolares».

31 Obligatoria para todos los municipios.

32 Obligatoria para los municipios con una población superior a los 20.000 habitantes. 
cimiento y adecuada prestación de los servicios mínimos». Claro ejemplo del papel que se quiere otorgar al nivel provincial, pero que debe ser entendido respecto a los municipios que tengan una población superior a los 20.000 habitantes.

Dicho lo anterior, las novedades más relevantes se centran en el ejercicio efectivo de las competencias mínimas u obligatorias y el procedimiento articulado para garantizar el mismo ${ }^{33}$. En este punto, el apartado 2 comienza por recoger la necesidad de regular el «coste estándar» del servicio, advirtiendo que se hará por real decreto del gobierno, que se ocupará de establecer el mismo determinando la periodicidad y procedimiento de evaluación y las condiciones en que los municipios deberán publicitar el coste y la eficiencia de los mismos. Semejante exigencia pretende aportar claridad, seguridad jurídica y, lo que es más importante, objetividad a la hora de lograr ejecutar las exigencias del art. 26 respecto a la prestación de las competencias en él recogidas. Ahora bien, no está exento de polémica desde el momento en que se trata de una norma estatal (título competencial), así como en atención a la falta de previsión de elementos correctores del coste del servicio (uniformidad del modelo) y de la posibilidad de que fuera necesario establecer en la propia ley los criterios a seguir para determinar el coste estándar. Respecto a los elementos correctores es importante destacar la diversidad municipal española y el agravio que se puede derivar si al establecer el coste estándar se hace — simple y exclusivamente- en atención a una población determinada (cuya cifra ya conocemos: los 20.000 habitantes). Establecido el coste, a continuación procederá a determinarse el importe en atención al simple criterio poblacional. Pues bien, este resultado determinará la viabilidad o no del servicio a prestar y será manifiestamente contrario a la realidad de las cosas. Incluso para dos municipios con la misma población pero con una realidad diferente (como puede ser el asentamiento físico de su población: diseminada en un caso, centralizada en otro). Máxime si el mecanismo se emplea para «demostrar» la ineficacia de los pequeños municipios a la hora de prestar los servicios públicos mínimos u obligatorios.

Asimismo llama especialmente la atención que el modelo propuesto pueda suponer la ruptura de la necesaria seguridad jurídica y coherencia

33 Son muy interesantes las objeciones metodológicas planteadas por Velasco Caballero en relación al concepto de «coste estándar» que maneja el informe elaborado por el IEF. En este sentido véase Francisco Velasco Caballero, «Sobre el Anteproyecto de Ley de racionalización y sostenibilidad de la Administración Local: una reforma sin fundamento empírico y, por tanto, arbitraria», op. cit. 
normativa, desde el instante en el que a la hora de referirnos a las competencias municipales debamos emplear la expresión de «relativas competencias mínimas u obligatorias de los municipios españoles» ${ }^{34}$, pues en función de los resultados se les podrán retirar todas o sólo algunas de ellas. Lo que encierra un problema en sí mismo en aras a lograr la necesaria racionalización del modelo, afectando directamente a la seguridad jurídica y a la propia coherencia normativa. Todo ello sin olvidar que vamos a encontrarnos con municipios que hayan realizado una labor impecable, logrando la tan importante estabilidad presupuestaria, pero quedando fuera del parámetro económico establecido por la simple razón de su población.

Finalmente se debe reflexionar sobre las consecuencias de centralizar las competencias sin prever la supresión del municipio en atención al instante en el que se celebren nuevamente elecciones municipales. Si poco sentido tiene mantener una estructura vacía o cuasivacía de competencias (más allá de las dudas de constitucionalidad que ello plantea), menos interesante resulta en atención a las elecciones municipales que terminarán por celebrarse. Ésta es una importante cuestión sobre la que debería pronunciarse el texto, enfrentándose a la consecuencia evidente del modelo que el ALRSAL propone. Ahora bien, si el mencionado modelo huye del problema de la planta orgánica municipal, otro tanto podrá deducirse de regular los resultados a los que más de la mitad de los municipios actuales se verán avocados.

Llegados a este punto, el ALRSAL recoge el procedimiento a seguir para determinar la prestación común y obligatoria de las competencias mínimas y obligatorias de los municipios, afectando a todas las previstas en el art. 26, y con carácter preferente cuando tenga por objeto determinados servicios $^{35}$. Al respecto llaman la atención dos cuestiones:

a) En primer lugar, la falta de coherencia en la terminología empleada en los apartados 1 y 4 , siendo curioso a su vez que queden fuera, fundamentalmente, competencias que serán obligatorias para todos los municipios con independencia de su población. Lo que, al parecer, no les otorga el carácter de preferentes.

${ }^{34}$ Cuestión ésta que será extrapolable al resto de competencias a ejercer por los municipios (propias ex art. 25, delegadas e impropias).

35 a) residuos sólidos urbanos; b) abastecimiento de agua potable a domicilio y evacuación y tratamiento de aguas residuales; $c$ ) infraestructura viaria; d) evaluación e información de situaciones de necesidad social y la atención inmediata a personas en situación o riesgo de exclusión social; e) protección civil, prevención y extinción de incendios; f) transporte colectivo de viajeros; $g$ ) instalaciones culturales y deportivas. 
b) En segundo lugar, se debe reflexionar sobre la diferencia existente entre asistencia strictu sensu (que permita al municipio cumplir con las previsiones legales) y establecimiento y prestación del servicio por parte de la diputación. Al respecto se trata de una diferencia más derivada de las consecuencias de incumplir, sumada a la población del municipio. Es decir, partiendo del incumplimiento de las exigencias económicas a la hora de prestar el servicio público, no es lo mismo que tenga más o menos de 20.000 habitantes. En el primer caso, plan de viabilidad y asistencia provincial (salvo que voluntariamente el municipio se sume a la prestación común). En el segundo, elevación de la competencias y asunción por la provincia u órgano equivalente (centralización).

Dicho procedimiento tiene por objetivo determinar si el municipio cumple o no con el coste estándar de los servicios y plantea ciertas dudas. La más elemental, porque dicho criterio debería preocupar con independencia de la población del municipio. Pero no parecer ser así, pues para el Anteproyecto el problema fundamental reside en los que tienen una población menor a los 20.000 habitantes, por entenderlos «objetivamente incapaces». Lo que no significa que no se encuentren todos sometidos al oportuno control de la calidad de los servicios, como así se desprende de la disposición adicional sexta, «Evaluación de los servicios municipales», sino que por debajo de dicha cifra es obligatoria la prestación común del servicio a nivel provincial o infraprovincial. Ello será así cuando, en razón de la naturaleza del servicio, la población o la sostenibilidad financiera no cumpla con el coste estándar de los servicios o sea ineficiente en atención a las economías de escala.

En nuestra opinión, el verdadero problema reside en las verdaderas intenciones del Anteproyecto: lograr la supresión de municipios. Es decir, ésa será la consecuencia lógica del modelo propuesto. En este punto debemos centrar nuestra atención en la referencia a las economías de escala, por cuanto la misma no parece ser inocente. Continuando con las reflexiones realizadas con anterioridad, parece clara la desconfianza que el ALRSAL muestra respecto de los pequeños municipios cuya población está por debajo de la cifra de los 20.000 habitantes. De tal forma que la mejor manera de evitar una evaluación positiva de los servicios a prestar por los mismos, o al menos con la clara intención de dificultar seriamente que la misma se pueda producir, se deriva precisamente del establecimiento de dicho concepto económico cuyo resultado será, inevitablemente, la elevación del ejercicio de la competencia a nivel provincial o equivalente. Así, el apartado 3 establece que: 
- En los municipios de menos de 20.000 habitantes, las diputaciones o los cabildos o consejos insulares asumirán el ejercicio de las competencias para la prestación común y obligatoria, a nivel provincial o infraprovincial, de los servicios previstos en este precepto, estableciéndose al respecto que en el plazo de un mes desde la comunicación a la diputación provincial u órgano equivalente del resultado negativo de la evaluación de los servicios, y previo informe de la Comunidad Autónoma, se adoptará por mayoría simple de los diputados o equivalentes. Transcurrido el plazo sin haberse adoptado acuerdo se entenderá aprobado (silencio positivo).

- Cuando sean uno o varios municipios quienes voluntariamente soliciten su incorporación al servicio común, bastará mayoría simple de los diputados o equivalente e informe de la Comunidad Autónoma. En este caso, lo que se ahorra es el procedimiento para evaluar el coste del servicio.

- Cuando se trata de municipios con más de 20.000 habitantes los que voluntariamente soliciten incorporarse a esta asistencia bastará la mayoría simple de los diputados o equivalentes. Prescindiéndose en este caso, a su vez, de la necesidad del informe de la Comunidad Autónoma.

- Siendo necesario en cualquiera de los tres supuestos la aprobación por el Pleno del Ayuntamiento.

Ahora bien, más allá de los órganos responsables de pronunciarse (municipio, provincia u órgano equivalente y Comunidad Autónoma), las consecuencias más importantes se derivan en atención al incumplimiento de las previsiones económicas. Obligatoriedad sólo para los municipios de menos de 20.000 habitantes. Por lo que habrá que preguntarse sobre las consecuencias para el resto, más allá de que voluntariamente soliciten incorporarse a la prestación común del servicio. En nuestra opinión, se limita - lo que no es poco- al establecimiento de un plan de viabilidad económica y a importantes límites respecto al ejercicio de otras competencias en tanto en cuanto los servicios mínimos u obligatorios no estén debidamente prestados y no exista estabilidad presupuestaria en los términos que hemos señalado al analizar las competencias propias ex art. 25, apartados 3, 4 y 5, LBRL.

Finalmente, y al margen de una previsión razonable respecto a las Comunidades Autónomas uniprovinciales, se regulan también las importantes consecuencias ante el redimensionamiento y reubicación de la prestación de las competencias mínimas u obligatorias en los casos en los que 
pasen a ser prestadas por la Diputación Provincial u órgano equivalente: a) en atención a los medios materiales y personales (apartado 3, párrafo 6); b) en atención a la forma de gestión; c) en atención a las tasas o precios públicos (apartado 5); d) en atención a la titularidad de la competencia, estableciendo su traslación cuando la misma sea asumida por una administración superior a la municipal y al ejercicio de la potestad reglamentaria para la regulación de las tasas o precios públicos; e) en atención al plazo de asunción del servicio, por un plazo mínimo de cinco años (apartado 6, párrafo final), y a la regulación del posible acuerdo de reversión de la competencia cuando se den ciertas circunstancias (apartado 7).

Como se puede observar, la presente reforma pone su énfasis en el municipio a efectos de racionalizar el modelo y en la provincia a los efectos de articular las soluciones que permitan cumplir con la estabilidad presupuestaria, sostenibilidad financiera y la eficiencia desde la perspectiva de la economía de escala a la hora de prestar servicios públicos. En este sentido, con la finalidad de reforzar la provincia, el ALRSAL procede a la modificación del art. 31.2 LBRL en el que se hace referencia a los fines propios y específicos de la provincia, incorporando al apartado $b$ ) un inciso final del siguiente tenor: «asumiendo la prestación común y obligatoria en los términos establecidos en el art. 26.3» (referido a las competencias mínimas u obligatorias). Su evidente consecuencia es elevar la importancia que se otorga a la provincia respecto a la prestación integral y adecuada en la totalidad del territorio provincial de los servicios de competencia municipal. Dicho lo cual se mantiene la posibilidad de otorgar subvenciones y ayudas con dicho propósito. Es decir, este artículo pretende ser una solución menos drástica que la relativa a la prestación común y obligatoria. Ahora bien, la duda es cuándo procede, debiendo entender que será posible no para los municipios que tengan una cifra inferior a los 20.000 habitantes e incumplan con las nuevas exigencias económicas, sino para los municipios de más de 20.000 habitantes o los de menos que cumplan con las mismas (lo que no deja de ser un contrasentido).

Más allá del fortalecimiento que se deriva de las consecuencias - inevitables- de la evaluación de los servicios mínimos en atención a la «economía de escala» y que le otorgan un papel principal a la provincia, ésta sale fortalecida a su vez por la introducción de otras modificaciones relativas a su posición y sus funciones ${ }^{36}$. Estando, eso sí, los servicios provinciales

36 Así, a los efectos de la aprobación del Plan Provincial de cooperación a las obras y servicios de competencia municipal se incluye un nuevo apartado c) del número anterior 
igualmente sujetos a la evaluación de acuerdo a los principios de sostenibilidad y eficiencia (y, por ende, al real decreto del gobierno).

La consecuencia del modelo trascrito es la evidente potenciación del nivel provincial o nivel equivalente, prescindiendo de adoptar otras soluciones que supongan fijar el ejercicio efectivo de las competencias a nivel de las mancomunidades u otras realidades locales ya existentes. Más allá de esta posibilidad, el ALRSAL ahonda, como no podía ser de otra manera, en la línea marcada por la necesaria capacidad para prestar competencias municipales. A saber, mediante la supresión, en esta ocasión sí de manera directa, de las entidades locales menores y adoptando medidas tendentes a la supresión de las mancomunidades de municipios ${ }^{37}$; realidad especialmente importante en el ámbito sobre el que incide de una manera especial el ALRSAL. Lo que deja clara la intención del Anteproyecto y la premisa económica que preside la misma: la reorganización de la planta orgánica municipal ante la evidente falta de capacidad por debajo de un determinado umbral poblacional.

Ahora bien, ¿es la provincia la solución al problema de falta de capacidad de los pequeños municipios? Al respecto debemos plantearnos ciertas cuestiones relativas —en este caso- a la verdadera capacidad de la provincia para desempeñar dichas funciones, pues serán necesarias nuevas medidas que permitan hacer efectivo su nuevo papel y sobre las que el ALRSAL guarda silencio. Por otro lado surge el dilema de la falta de democraticidad del nivel provincial ${ }^{38}$ o equivalente, ya que su

relativo a «la prestación de servicios de carácter supramunicipal y, en su caso, comarcal». Por otro lado, se hace referencia expresa [apartados $c$ ) y $d$ ), respectivamente] a garantizar el desempeño de las funciones públicas necesarias (apoyo en selección, formación) y dar soporte para la tramitación de procedimientos administrativos y realización de actividades materiales y de gestión asumiéndolas cuando aquéllos se las encomienden (muy interesante).

37 Al respecto véase la disposición adicional, «Evaluación de los servicios prestados por mancomunidades y entidades de ámbito territorial inferior al municipio», y la disposición transitoria cuarta, «Disolución de las mancomunidades de municipios». Cuestiones éstas que, sin embargo, exceden al objeto del presente trabajo. Debiendo advertir al respecto que, en cuanto a esta realidad, el problema real es de control efectivo, siendo el verdadero escollo el relativo a la Administración instrumental, origen y razón de ser de la superestructura organizativa derivada de la LBRL.

38 «El relevante problema de la prestación en determinados casos de los servicios públicos locales se resuelve de una forma discutible, pues no se confía en las mancomunidades ya existentes, sino que la responsabilidad se traslada a las diputaciones. Es decir, que unas Administraciones geográficamente más distantes y sin la adecuada representación democrática de los ayuntamientos de menor población serán las que gestionen servicios esenciales para esos vecinos». Véase Francisco Sosa WAGNER y Mercedes FuERTES, «Una reforma alicorta», op. cit., p. 19. Como señalan los propios autores, «de las posibles soluciones se ha optado por la menos democrática y la que podrá generar más problemas». 
elección es indirecta y no representa, más que proporcionalmente, a los intereses de los municipios afectados. Y lo que parece más relevante, ¿quién va a hacer frente al sobrecoste que se derive de la «provincialización» de las competencias municipales?. Cuestiones que simplemente planteamos pero sobre las que, sin ninguna duda, habrá que reflexionar en profundidad.

\section{B) Regulación de las competencias delegadas (art. 27 LBRL)}

La nueva redacción que se da al art. 27 LBRL, y cuyo contenido está relacionado con las competencias delegadas, pone de manifiesto - una vez más- la intención de clarificar el modelo competencial. Es decir, partiendo de que nos encontramos ante competencias que se ejercen con arreglo a la legislación del Estado o de las Comunidades Autónomas correspondientes (apartado 7), que para su efectividad es necesaria la aceptación por el municipio interesado (apartado 4) y que la Administración delegante podrá dirigir y controlar el ejercicio de los servicios delegados en los términos y con las consecuencias ya conocidas (apartado 3), la nueva regulación introduce las siguientes modificaciones.

Comienza por reducir las Administraciones delegantes, que serán el Estado y las Comunidades Autónomas en el ejercicio de sus respectivas competencias y quedando fuera ya la referencia que se hacía a «otras entidades locales».

Se exige que contribuya a eliminar duplicidades administrativas y ser acorde con la legislación de estabilidad presupuestaria y sostenibilidad financiera, yendo más allá de la mera referencia, que ahora se mantiene, de que debe mejorar la eficiencia de la gestión pública (apartado 1, párrafo segundo).

Respecto de las novedades relacionadas con los contenidos formales de la delegación, se advierte que no podrá ser inferior a cinco años y deberá fijar un control de eficiencia (apartado 1, párrafo tercero). Asimismo, la delegación deberá acompañar una memoria económica (apartado 1 , cuarto párrafo).

Como medidas concretas para evitar las duplicidades y para mejorar la transparencia de los servicios públicos, racionalizando el modelo y generando ahorro neto de recursos, la Administración del Estado y de las Comunidades Autónomas podrán delegar, siguiendo criterios homogéneos: 
- En los municipios de más de 20.000 habitantes (límite objetivo clave dentro del concepto de la cifra que diferencia la capacidad real - para el ALRSAL - a los efectos de poder prestar servicios que excedan de sus competencias mínimas obligatorias). Ahora bien, al respecto se puede llegar a discutir si tiene sentido, pues todavía existe una umbral mayor a estos efectos (municipios con más de 50.000 habitantes). Dicho lo cual no debe ser problemático, pues nos encontramos ante unas competencias cuya gestión en términos económicos viene respaldada y se permite su renuncia en caso de poder afectar a las competencias propias (apartado 6). Con ello se trata de hacer el servicio más eficiente, no lo contrario, y se parte de la base —discutible como ya hemos expresado- de la capacidad real del municipio a partir del umbral de los 20.000 habitantes.

- Para el ejercicio de una serie de competencias, a las que se podrán añadir otras, lo que siendo razonable puede generar cierta inseguridad jurídica, pero que es respetuoso con la autonomía. Sea como fuere, deberán cumplir las previsiones establecidas en el art. 27 LBRL. Dicho lo cual es importante el esfuerzo clarificador que se deriva de la lista creada, en la que se establecen como posibles competencias delegadas las siguientes:

1. Vigilancia y control de la contaminación ambiental.

2. Protección del medio natural.

3. Conservación o mantenimiento de centros sanitarios asistenciales de titularidad de la Comunidad Autónoma.

4. Creación, mantenimiento y gestión de las escuelas infantiles de educación de titularidad pública de primer ciclo.

5. Realización de actividades complementarias en los centros docentes.

6. Gestión de instalaciones culturales de titularidad de la Comunidad Autónoma o del Estado, con estricta sujeción al alcance y condiciones que se derivan del art. 149.1.28 de la Constitución Española.

7. Gestión de instalaciones deportivas de titularidad del Estado o de las Comunidades Autónomas, incluyendo las situadas en los centros docentes cuando se usen fuera del horario lectivo.

8. Inspección y sanción de establecimientos y actividades comerciales.

9. Promoción y gestión turística. 
10. Comunicación, autorización, inspección y sanción de los espectáculos públicos.

11. Liquidación y recaudación de tributos propios de la Comunidad Autónoma o del Estado.

12. Inscripción de asociaciones, empresas o entidades en los registros administrativos de la Comunidad Autónoma o de la Administración del Estado.

13. Gestión de oficinas unificadas de información y tramitación administrativa.

Ahora bien, la misma debe ser objeto de detenido análisis para evitar reiteraciones competenciales conducentes a problemas de coherencia normativa y, a la postre, a nuevas duplicidades.

Igualmente importante es la previsión del apartado 5, en virtud de la cual la delegación deberá ir acompañada en todo caso de la correspondiente financiación (siendo nula sin la misma). El incumplimiento faculta a la Administración Local delegada para compensarla automáticamente con otras obligaciones financieras que ésta tenga con aquélla. Asimismo, en el apartado 6 se establece dicho incumplimiento como una de las causas de la revocación o renuncia de la delegación, entre las que está el incumplimiento de las obligaciones financieras de la Administración delegante o cuando por circunstancias sobrevenidas se justifique suficientemente la imposibilidad de su desempeño sin menoscabo del ejercicio de sus competencias propias (el acuerdo de revocación o renuncia se adoptará por el pleno). La primera previsión supone una garantía absoluta de las medidas adoptadas para garantizar la correspondiente financiación ${ }^{39}$. En cuanto a la segunda, debemos destacar que el actual modelo establece un sistema de tres escalones que, siendo acorde con el sentido común, pone de manifiesto la importancia que tiene para el modelo el cumplimiento de las competencias municipales. En este sentido, entendemos que sólo se podrá pasar al siguiente escalón cuando el anterior esté cubierto en atención a las nuevas exigencias económicas.

Por tanto, el municipio deberá cumplir con las obligaciones mínimas u obligatorias (en caso contrario, si tiene menos de 20.000 habitantes, prestación común obligatoria; si tiene más, plan de viabilidad); competencias propias, en los términos establecidos en la legislación del Estado y de las

$39 \mathrm{Al}$ respecto véase el nuevo art. 57 bis LBRL, «Garantía de pago en el ejercicio de competencias delegadas». 
respectivas Comunidades Autónomas. Instante en el cual podrá prestar las competencias delegadas ${ }^{40}$.

Finalmente debemos abordar ahora la reorganización competencial realizada por el ALRSAL en relación a ciertas competencias que hasta ahora venían prestando los municipios y que a partir de la reforma se elevan a nivel autonómico. En este sentido debemos destacar, a su vez, cómo en dicho proceso, y al margen de otras alteraciones, se ha procedido a la supresión de las competencias en materia de asistencia social, sanidad y educación. En esta línea resulta importante la disposición transitoria octava, «Asunción por las Comunidades Autónomas de las competencias relativas a la salud y la educación», y la disposición transitoria undécima, «Asunción por las Comunidades Autónomas de las competencias relativas a servicios sociales», que podrán seguir ejerciéndose pero no como competencias propias mínimas u obligatorias (caso de los servicios sociales, ahora reducidos a la atención primaria) o como competencias propias (caso de la educación y de la sanidad). Unas y otra pasan ahora a formar parte de las materias incluidas en el art. 27, por lo que pasan a ser —en su caso- competencias delegadas. Lo que, en nuestra opinión, tiene más sentido. Máxime si tenemos en cuenta que de ser así estarían presididas por la voluntariedad de la aceptación y por la obligatoriedad de financiación del servicio. El problema reside en la mala técnica legislativa y en las dificultades para hacer efectiva la traslación de la competencia y las consecuencias para el ámbito local, que seguirá viéndose obligado a financiar ciertos servicios aun sin ostentar su titularidad ni los medios económicos para ello.

\section{C) Supresión de las competencias complementarias (antiguo art. $28 \mathrm{LBRL}^{41}$ )}

Se suprime in totum el contenido del art. 28 LBRL, lo que supone un importante avance al evitar que por este cauce proliferen, en pro de la defensa de los intereses locales, las competencias impropias, acabando a su vez con la falta de seguridad jurídica que se deriva de una previsión como

${ }^{40} \mathrm{Al}$ que se puede sumar, excepcionalmente, el ejercicio de competencias impropias en los términos del nuevo apartado 4 del art. 7 LBRL.

${ }^{41}$ Sobre su régimen jurídico en atención al art. 28 LBRL véase Luis OrTEga Álvarez y Francisco Puerta Seguido, «Comentario al art. 28 LBRL», en Manuel Rebollo Puig y Manuel IzQuierdo CarRasco (dirs.), Comentarios a la Ley Reguladora de las Bases del Régimen Local, t. I, Valencia, Tirant lo Blanch, 2007, pp. 747 y ss. 
la establecida en el art. 28 LBRL al atribuir a los municipios, a través de una cláusula general, la posibilidad de realizar actividades complementarias de las propias de otras Administraciones Públicas, especificándose al respecto las relativas a educación, cultura, vivienda, sanidad o protección del medio ambiente. Con ello se prioriza la claridad, la transparencia, la seguridad jurídica y la coherencia normativa por encima del derecho de los municipios a participar en cualquier competencia, dentro de las así estipuladas, para la oportuna defensa de sus intereses. Se trataba de una «oda» a la duplicidad de competencias, al sobredimensionamiento organizativo y al sobrecoste en la prestación de servicios públicos. Amén de los problemas derivados de la falta de conocimiento por parte del ciudadano de quién ejerce qué competencia. Supresión, por tanto, esencial dentro del objetivo marcado: «una Administración, una competencia». Es más, esta simple medida puede ser una de las que produzca efectos más inmediatos, provocando un importante ahorro al evitar la proliferación injustificada de competencias municipales. Al respecto es importante la disposición adicional sexta (evaluación de los servicios municipales) y la disposición transitoria novena (evaluación de las competencias impropias ejercidas por los municipios) y sus consecuencias competenciales ${ }^{42}$.

\section{D) Regulación de las competencias impropias: su significado, alcance $y$ limites a su prestación}

En este sentido, al art. 7 LBRL se le añade un párrafo 4 en el que se advierte que: «Las entidades locales sólo podrán ejercer competencias

42 En este punto debemos ser conscientes, en primer lugar, de la importancia que tiene la disposición adicional sexta, en virtud de la cual se exige la «evaluación de servicios municipales» con independencia de la población, de tal forma que su resultado y medidas a adoptar formará parte del plan de ajuste o del plan económico-financiero que, en su caso, tuviera en vigor el ayuntamiento. Se trata, por tanto, de someter a todos los ayuntamientos a un control real que permita determinar las competencias que se ejercen, distinguiendo al respecto su naturaleza jurídica (propias, delegadas, impropias) y, por ende, sus consecuencias, para lo cual es importante el umbral poblacional. Siendo al respecto importante la previsión de la disposición adicional decimotercera, en la medida en que exige que se especifique el «coste real de los servicios» para poder compararlo con el coste estándar, todo ello con independencia de la forma, proporción y cuantía en que finalmente sean financiados. Asimismo, debe tenerse en cuenta que dicha evaluación es extensiva a los servicios prestados por mancomunidades y entidades de ámbito territorial inferior al municipio (disposición adicional séptima) en relación, a su vez, con la disolución de mancomunidades de municipios (disposición transitoria cuarta). 
impropias, entendiendo por éstas las distintas a las competencias propias y a las atribuidas por delegación, así como desarrollar actividades económicas cuando no se ponga en riesgo financiero la realización de las competencias propias, no haya duplicidades con las competencias autonómicas y se garantice la suficiencia financiera de las nuevas competencias o actividades económicas, respetando en todo caso el principio de eficiencia y el resto de requerimientos de la legislación de estabilidad presupuestaria y sostenibilidad financiera. A estos efectos será necesario el informe previo de la Comunidad Autónoma en el que se señale la inexistencia de duplicidades y del interventor de la entidad local sobre la sostenibilidad financiera de las nuevas competencias».

Por tanto, son competencias impropias las que no son propias o delegadas, y se podrán llevar a cabo siempre y cuando:

- No se ponga en riesgo financiero la realización de competencias propias.

- No haya duplicidades con las competencias autonómicas.

- Se garantice la suficiencia de las nuevas competencias.

- Se respete en todo caso el principio de eficiencia y el resto de requerimientos de la ley de estabilidad presupuestaria y estabilidad financiera.

- Sea necesario informe previo de la Comunidad Autónoma y del interventor de la entidad local (los cuales deberían limitarse a un control de estricta legalidad, pues de lo contrario supondrían una clara vulneración de la autonomía local).

Como observaciones a realizar, a tenor de la redacción dada al art. 7.4. LBRL, las competencias impropias parecen circunscribirse al ámbito de las competencias autonómicas. Lo que no tienen mucho sentido, con independencia de que la mayor conflictividad se produzca entre el nivel autonómico y local. Asimismo, al no prohibirse en el ámbito de las competencias estatales, podría llevar a error, por cuanto en este supuesto sí podría haber duplicidad. En segundo lugar, nos parece interesante la necesidad de elaborar informes a los efectos de dar oportuno cumplimiento a los contenidos del presente apartado. Y lo que es más importante, nos encontramos ante la necesaria definición de una realidad que, habiendo dado mucho rédito en épocas anteriores, se había convertido en un importante problema presupuestario por falta de medios para su oportuno ejercicio o, existiendo éstos, por la falta de seguridad jurídica en torno a unas competencias que, en puridad, no eran tales. Máxima expresión, por tanto, del 
abuso en el ejercicio de la autonomía local por parte de las entidades locales. En la actualidad sólo tendrán lugar cuando con su ejercicio no se pongan en riesgo las competencias propias, se dispongan de los medios suficientes para su ejercicio y no afecte a la estabilidad presupuestaria.

$\mathrm{Al}$ respecto debemos tener en cuenta la disposición transitoria novena, relativa a la «Evaluación de las competencias impropias ejercidas por los municipios», tomando como referencia el coste estándar de los servicios. La evaluación determinará en primer lugar si son adecuadas o no. En el primer supuesto dejarán de prestarse; en el segundo — por entender que respetan el art. 7.4- se determinará su coste y la necesidad —o node presentar una propuesta que racionalice su ejercicio. Lo que se pretende con este apartado es hacer un «guiño» a aquellos municipios que cumplan con sus obligaciones respetando la necesaria estabilidad presupuestaria y dando margen al ejercicio de otras competencias que les permita defender los intereses propios en pro de la autonomía constitucionalmente consagrada.

\section{CONCLUSIONES}

Llegados a este punto podemos destacar la trascendencia del nuevo modelo competencial en el que sin ninguna duda se pretende lograr su clarificación, antesala necesaria para lograr la tan ansiada seguridad jurídica, coherencia normativa y, como consecuencia de todo ello, una necesaria racionalización de la Administración Local. En este punto resulta fundamental destacar la importancia que tienen las siguientes premisas establecidas por el ALRSAL y analizadas a lo largo del presente trabajo. Sólo así se podrá entender el modelo propuesto:

- En primer lugar, los principios constitucionales relativos a la necesaria estabilidad presupuestaria, sostenibilidad y eficiencia económica (ex art. $135 \mathrm{CE})$.

- En segundo lugar, el principio «una Administración, una competencia».

- En tercer lugar, el establecimiento de un modelo inspirado en la necesaria capacidad para prestar competencias, cuya consecuencia objetiva se determina en relación a la población exigida: los 20.000 habitantes. Por debajo de dicha cifra, y fundamentalmente de los 5.000 habitantes, será difícil que haya «vida municipal». 
- En cuarto lugar, la articulación de unas medidas de control financiero y presupuestario para el ejercicio de los servicios municipales y que se agravan por debajo de la mencionada población (y dentro de ésta para los municipios con menos de 5.000 habitantes) y en atención a las competencias mínimas u obligatorias. Siendo al respecto la medida estrella, la necesidad de superar el «coste estándar» que vendrá determinado por un real decreto del gobierno.

- En quinto lugar, la articulación de un sistema escalonado, a los efectos de que el municipio pueda prestar competencias: propias (mínimas u obligatorias y propias), delegadas e impropias en los términos explicados. Lo más relevante es que para poder prestar competencias de un escalón superior debe cumplirse con los requisitos de estabilidad presupuestaria previstos en la norma para el escalón inmediatamente anterior, garantizando así su prestación efectiva y respetando los parámetros de calidad establecidos. Se trata de un modelo en el que se instaura la prelación competencial. De tal forma que los municipios no podrán prestar competencias no obligatorias (propias o delegadas) o impropias si no tiene cubiertas las obligatorias, y así sucesivamente. Ahora bien, se corre el riesgo de que pasemos a un modelo caracterizado por las «relativas competencias municipales», en la medida que las mismas van a depender de un sinfín de variables.

Modelo que exige una valoración desde un punto de vista formal, mejorando su técnica legislativa, pero que, en lo que ahora más nos interesa, encierra problemas relacionados con la propia constitucionalidad del mismo. Nos estamos refiriendo a sus consecuencias sobre la planta orgánica municipal, a los problemas derivados del establecimiento de un «coste estándar» y su regulación mediante real decreto del gobierno, y a las medidas de control por si resultan contrarias a la autonomía local.

En primer lugar, el nuevo modelo competencial puede contravenir la autonomía local constitucionalmente consagrada como consecuencia de que la ALRSAL no se replantea la planta orgánica municipal, al menos de manera directa. Y ello es lo importante, pues a la luz del texto es evidente que el gobierno pretende, a todas luces, una reducción de municipios. Ésa y no otra será la consecuencia del vaciamiento competencial derivado del modelo que se pretende instaurar, basado en la capacidad del municipio y centrando la misma a partir de los 20.000 habitantes. El hecho de que en el texto no se proponga una reducción del número de municipios de manera expresa no significa que dicha premisa haya quedado erradicada. 
Al menos el ALRSAL es consecuente con su planteamiento, razonable o no, ya que pretende a su vez la supresión de la personalidad jurídica de las entidades locales menores ${ }^{43} \mathrm{y}$ de las mancomunidades de municipios ${ }^{44}$. En ambos casos coherentes con el espíritu de la reforma por entender que son contrarias a la necesaria estabilidad presupuestaria. Ahora bien, en nuestra opinión las consecuencias que se derivan de la regulación competencial y las medidas adoptadas en materia organizativa ponen de manifiesto la necesidad de replantear la solución, enfrentándose directamente al problema derivado de la planta orgánica municipal. En este sentido nos podemos centrar en las mancomunidades ${ }^{45}$ (1.021 en todo el territorio nacional) como base para determinar una nueva planta orgánica municipal en la que los municipios integrantes de esa nueva realidad pasen a ser entidades locales menores con personalidad jurídica propia y un cierto grado de competencias. Con ello se respeta el sentimiento municipal sin caer en el romanticismo, pues la falta de capacidad que plantea el Anteproyecto es una evidencia difícilmente discutible ${ }^{46}$. Dicho lo cual los esfuerzos deben centrarse primeramente en las consecuencias que se van a derivar del nuevo régimen competencial: el vaciamiento de competencias y la supresión - por la vía indirecta- de municipios.

En segundo lugar debe realizarse una profunda reflexión sobre las medidas establecidas para hacer efectiva la valoración de la calidad de los servicios municipales. Un modelo en el que no sólo se tiene presente la calidad del servicio, sino que su prestación debe responder a criterios relacionados con «la economía de escala», todo ello con independencia de que se exija su comparación con el coste real del servicio. La cuestión estriba en determinar si dicho coste, que corresponderá determinar a un real decreto del gobierno -más allá ahora de los evidentes problemas relativos al título competencial—, supone, en los términos que está recogido, un respeto a la autonomía local y el mejor mecanismo para lograr la tan ansiada eficiencia y, a colación de la misma, la sostenibilidad de la Administración Local y de la estabilidad presupuestaria. En este punto, como advierte

${ }^{43}$ Arts. 3.2 y 45 LBRL, modificados por la ALRSAL.

${ }_{44}$ Disposición adicional séptima, «Evaluación de los servicios prestados por mancomunidades y entidades de ámbito territorial inferior al municipio», y disposición transitoria cuarta, «Disolución de mancomunidades de municipios», de la ALRSAL.

${ }^{45} \mathrm{Su}$ verdadero problema debemos verlo en atención a la ausencia de control real.

${ }^{46}$ En esta línea, más importancia tienen en términos económicos las medidas que se articulan desde un punto de vista también organizativo y que tienen como propósito la racionalización y reducción de la Administración instrumental, verdadero problema y origen del sobredimensionamiento local en términos organizativos. 
el informe elaborado por la Comisión Nacional de la Competencia ${ }^{47}$, siendo loable la introducción de elementos que busquen la evaluación de la eficiencia en la gestión de los servicios públicos, el modelo propuesto plantea dudas - por su parquedad - desde un punto de vista procedimental, normativo (se difiere a un futuro Reglamento del Gobierno) y en cuanto a sus consecuencias en caso de evaluación negativa. En este punto se hacen unas interesantes reflexiones que llevarían a la «sustitución de las referencias al coste estándar por la necesidad de que los servicios prestados por las entidades locales se realicen en mayor competencia» ${ }^{48}$. Sea como fuere, lo cierto es que son muchas las cuestiones que rodean al concepto del «coste estándar» y sobre las que hemos incidido a lo largo del trabajo.

En tercer lugar debemos tener presente —-más allá de que exceda al objeto del presente trabajo- que las medidas de control auspiciadas por el texto no deben ser entendidas como contrarias a la autonomía local per se, siempre y cuando se centren en determinar la legalidad — que no oportunidadde las actuaciones municipales. De lo que no cabe ninguna duda es que el nuevo escenario va a suponer un redimensionamiento de la autonomía local en atención a los nuevos principios de estabilidad presupuestaria y sostenibilidad económica, con motivo de la necesaria lectura de la norma fundamental al albur de los mismos. Para la consecución de tan importante principio el nuevo modelo pone el acento en tres cuestiones especialmente relevantes. A saber, las competencias, la organización y el control financiero y presupuestario del municipio. Es éste y no otro el núcleo de la reforma: el municipio, su necesaria racionalización y su oportuno control. Ahora bien, ello no puede suponer el desconocimiento de la autonomía local como un principio constitucionalmente consagrado que debe ser, asimismo, respetado.

Sirva el presente trabajo como una reflexión ${ }^{49}$ en torno a una compleja realidad como es el régimen local ${ }^{50}$, que le permita volver a ocupar el lugar

${ }^{47}$ CNC, IPN 88/13, Anteproyecto de Ley de Racionalización y Sostenibilidad de la Administración Local, aprobado el 13 de marzo de 2013 (disponible en www.cncompetencia.es).

${ }^{48}$ CNC, IPN 88/13, Anteproyecto de Ley de Racionalización y Sostenibilidad de la Administración Local, aprobado el 13 de marzo de 2013, pp. 15 y ss., punto III.7 (disponible en www.cncompetencia.es).

${ }_{49} \mathrm{Al}$ hilo de la cual habrá que atender a la de otros muchos autores, así como a las esperadas alegaciones de los ayuntamientos, de las provincias y de las Comunidades Autónomas. Asimismo, será sumamente interesante atender los argumentos que esgriman FEMP o el COSITAL. Todo ello con el firme propósito de abordar la mejor de las reformas de la Administración Local.

${ }^{50}$ Advirtiendo que, una vez analizado el nuevo régimen jurídico de las competencias municipales, debemos recordar que la presente reforma, teniendo como elemento central a 
que le corresponde y arrojando luz — por pequeña que sea— a los efectos de analizar las dudas que rodean al nuevo modelo planteado. Invitando a la reflexión de sus posibles consecuencias indirectas, sobre todo desde la perspectiva de la autonomía local constitucionalmente consagrada. De lo que no cabe duda es que debemos dar una respuesta eficaz y constructiva al nuevo paradigma surgido de la crisis y concretado en nuestra norma fundamental a través del art. 135 CE: estabilidad presupuestaria, sostenibilidad de la Administración y eficiencia. Principios que van a exigir una modulación de la Administración Local y, por ende, del principio de autonomía que inspira y da sentido a la misma. Pero sin llegar al extremo de buscar su supresión, por resultar —a todas luces— contraria a nuestra norma fundamental.

\section{BIBLIOGRAFÍA}

Álvarez Conde, E., y Souto Galván, C. (coords.), La constitucionalización de la estabilidad presupuestaria, Madrid, Instituto de Derecho Público, 2012.

Bassols Coma, M. «La reforma del art. 135 CE y la constitucionalización de la estabilidad presupuestaria. El proceso parlamentario de elaboración de la reforma constitucional», REDA, núm. 155, 2012.

Carro Fernández-Valmayor, J. L., «El debate sobre la autonomía municipal», RAP, núm. 147, septiembre-diciembre de 1998.

Cosculluela Montaner, L.; Medina Alcoz, L.; Hernando Rydings, M., y Carbonell Porras, E. (coords.), Crisis económica y reforma del régimen local, Cizur Menor, Civitas Thomson Reuters, 2012.

dicha entidad local, procede a realizar otras modificaciones, todas ellas tendentes a lograr su correcta puesta en marcha. En este sentido, tenemos las medidas en materia de personal (disposiciones adicionales undécima y decimoquinta), económicas (disposición adicional decimonovena, compensación de deudas), patrimoniales (disposiciones adicionales decimoquita y decimosexta), competenciales (sobre los convenios firmados al albur de las competencias y servicios municipales y sobre la traslación de las competencias en materia de educación y asuntos sociales) (ex disposición adicional decimoquinta y disposiciones transitorias octava y undécima) y organizativas (disposiciones transitorias segunda, consorcios, y cuarta, mancomunidades). Siendo del todo insuficientes las modificaciones articuladas sobre la Ley de Haciendas Locales, verdadero caballo de batalla, pues supone dejar al margen un importante principio como el de suficiencia financiera consagrado constitucionalmente ex art. 142 CE y que debe ser introducido en la ecuación de una vez por todas, instaurando un nuevo modelo de financiación, a todas luces insuficiente y origen de muchos de los problemas que acucian a día de hoy a los municipios españoles. En cuanto a la situación de las haciendas locales véase Antonio López DíAz, «Las haciendas locales en España: situación actual y perspectivas de futuro», en Luis Cosculluela Montaner, Luis Medina Alcoz, María Hernando Rydings y Eloisa Carbonell Porras (coords.), Crisis económica y reforma del régimen local, op. cit., pp. 225-270. 
Embid Irujo, A., «Crisis económica y reforma local», Anuario Aragonés de Gobierno Local, Zaragoza, Institución Fernando el Católico, 2011.

Esteve Pardo, J., «Garantía institucional y/o función constitucional en las bases del régimen local», REDC, núm. 31, enero-abril de 1991.

Fanlo Loras, A., Fundamentos constitucionales de la autonomía local, Madrid, CEC, 1990.

Fernández-Miranda Fernández-Miranda, J., «El principio de autonomía local y la posible superación de la teoría de la garantía institucional», $R A P$, núm. 175, 2008 .

FERnÁndez TORRES, J. R., La creación de nuevos municipios por segregación, Valencia, Tirant lo Blanch, 2003.

García-Andrade GómeZ, J., «La reforma del art. 135 CE», RAP, núm. 187, 2012.

GARCía DE ENTERRÍA, E., Revolución francesa y administración contemporánea, Madrid, Civitas, 1985.

García FernÁndeZ, J., «Derecho constitucional y entidades locales. Sistema de fuentes y autonomía como fundamentos constitucionales básicos del Derecho local», Parlamento y Constitución. Anuario de las Cortes de Castilla-La Mancha, núm. 6, 2002.

García Morillo, J., La configuración constitucional de la autonomía local, Madrid, Diputación de Barcelona-Marcial Pons, 1998.

García RocA, J., «El concepto actual de autonomía local según el bloque de constitucionalidad», REALA, núm. 282, enero-abril de 2000.

IEF, «Informe sobre el ahorro potencial por establecimiento de un coste estándar en la prestación de servicios en el ámbito local».

- «Informe para la reforma de la financiación de las haciendas locales», Comisión para el estudio y propuestas de medidas para la reforma de la financiación de las haciendas locales, Ministerio de Hacienda, Secretaría de Estado de Hacienda, 2002.

Informe CNC, IPN 88/13, Anteproyecto de Ley de racionalización y sostenibilidad de la Administración Local, 13 de marzo de 2013 (disponible en www. cncompetencia.es).

Jiménez Asensio, R., «Las instituciones locales en tiempo de crisis: reforma institucional y gestión de recursos humanos en los gobiernos locales», Cuadernos de Derecho Local, núm. 26, Fundación Democracia y Gobierno Local, 2011.

LÓPEz DíAz, A., «Las haciendas locales en España: situación actual y perspectivas de futuro», en L. Cosculluela Montaner, L. Medina Alcoz, M. Hernando Rydings y E. Carbonell PorRas (coords.), Crisis económica y reforma del régimen local, Cizur Menor, Civitas Thomson Reuters, 2012.

MAP, Libro Blanco para la reforma del gobierno local, 2005.

Martí Del Moral, A., «La constitucionalización del principio de estabilidad presupuestaria», en L. Cosculluela Montaner, L. Medina Alcoz, M. Hernando Rydings y E. CARBOnell PorRas (coords.), Crisis económica y reforma del régimen local, Cizur Menor, Civitas Thomson Reuters, 2012. 
Muñoz Machado, S. (dir.), Tratado de Derecho Municipal, t. I, Madrid, Iustel, 2011.

Orduña Rebollo, E., «Nuevas aportaciones sobre el mapa municipal español», REAL, núm. 291, 2003.

Ortega Álvarez, L., «Las competencias propias de las corporaciones locales», en S. Muñoz Machado (dir.), Tratado de Derecho Municipal, t. I, Madrid, Iustel, 2011.

Ortega Álvarez, L., y Puerta Seguido, F., «Comentario al art. 28 LBRL», en M. Rebollo Puig y M. IzQuierdo Carrasco (dirs.), Comentarios a la Ley Reguladora de las Bases del Régimen Local, t. I, Valencia, Tirant lo Blanch, 2007.

Parada VázQuez, J. R., La segunda descentralización: del Estado autonómico al municipal, Madrid, Civitas, 2007.

Parejo Alfonso, L., Garantía institucional y autonomías locales, Madrid, IEAL, 1981.

— «La autonomía local en la Constitución», en S. MuÑoz Machado (dir.), Tratado de Derecho Municipal, t. I, Madrid, Iustel, 2011.

- «La garantía institucional y las competencias locales», en Informe sobre el gobierno local, Madrid, MAP-Fundació Pi-Sunyer, 1992.

Portillo Navarro, M. ${ }^{a}$ J., y Merino Estrada, V. (coords.), Crisis económica y entidades locales, Valladolid, Lex Nova-Thomson Reuters, 2012.

Rebollo Puig, M., «La supresión de los pequeños municipios: régimen, alternativas, ventajas e inconvenientes», REALA, núm. 308.

- «La crisis económica y la posibilidad de reducir el número de municipios», en L. Cosculluela Montaner, L. Medina Alcoz, M. Hernando Rydings y E. Carbonell Porras (coords.), Crisis económica y reforma del régimen local, Cizur Menor, Civitas Thomson Reuters, 2012.

Rebollo Puig, M., e IzQuierdo Carrasco, M. (dirs.), Comentarios a la Ley Reguladora de las Bases del Régimen Local, t. I, Valencia, Tirant lo Blanch, 2007.

SÁnchez Morón, M., «La distribución de competencias entre el Estado y las Comunidades Autónomas en materia de Administración Local», en S. MuÑOz Machado (dir.), Tratado de Derecho Municipal, t. I, Madrid, Iustel, 2011.

Sosa Wagner, F., «Los principios del régimen local», en S. Muñoz Machado (dir.), Tratado de Derecho Municipal, t. I, Madrid, Iustel, 2011.

Sosa Wagner, F., y Fuertes, M., «Una reforma alicorta», en El Mundo, viernes, 8 de marzo de 2013.

Velasco Caballero, F., «Autonomía municipal», ponencia presentada en el II Congreso de la Asociación Española de Profesores de Derecho Administrativo, Santander, 2 de febrero de 2007.

— «Sobre el Anteproyecto de Ley de racionalización y sostenibilidad de la Administración Local: una reforma sin fundamento empírico y por tanto arbitraria», en bttp://www.idluam.org/images/files/boletines/index_44_3_archivos/ Page426.htm, Instituto de Derecho Local-UAM, 2013.

VVAA, La Reforma Constitucional, Revista Teoría y Realidad Constitucional, núm. 29, 2012. 